\title{
APRENDIZAGEM DE CONCEITOS MATEMÁTICOS: perspectivas da educação inclusiva no município de Gravataí/RS
}

\author{
Camila da Silva Nunes \\ Marlise Geller
}

\section{Resumo}

Este artigo busca refletir sobre como os diferentes espaços escolares, a sala de aula regular da escola na perspectiva da educação inclusiva e o Atendimento Educacional Especializado, abordam conceitos matemáticos com os alunos. A partir de um recorte da tese de doutorado, analisamos as intervenções pedagógicas implementadas nesses espaços, com quatro alunos público-alvo da educação inclusiva, matriculados nos anos iniciais do ensino fundamental no município de Gravataí, Rio Grande do Sul (RS). Os resultados da pesquisa apontaram que as estratégias de intervenção utilizadas, como jogos pedagógicos, material concreto e tecnologias, potencializaram a aprendizagem matemática dos estudantes, possibilitando um maior envolvimento nas tarefas propostas, despertando, assim, o interesse pela aprendizagem de conceitos matemáticos iniciais. Por fim, observamos que as intervenções pedagógicas, oriundas do Atendimento Educacional Especializado, se sobressaem em relação à sala de aula regular, pois os estudantes frequentam esse espaço com interesse e curiosidade. Pode-se inferir que esse interesse se origine, devido as atividades serem propostas de forma individualizada ou em pequenos grupos, além de assumirem um caráter mais criativo.

Palavras-chave: educação matemática; intervenções pedagógicas; sala de aula regular; Atendimento Educacional Especializado; educação inclusiva.

LEARNING MATHEMATICAL CONCEPTS: perspectives of inclusive education in the city of Gravataí/RS

\begin{abstract}
This article aims to reflect on how different school spaces (regular school classrooms in the perspective of inclusive education, and the Specialized Educational Service) approach mathematical concepts with students. In a clipping of the doctoral thesis, we analyzed the pedagogical interventions carried out in these spaces, with four target students of inclusive education, enrolled in the early elementary education years in the city of Gravataí, Rio Grande do Sul (RS). The survey results showed that the intervention strategies used (such as educational games, concrete materials and technologies), heightened the mathematical learning of children through a ludic way, enabling a greater involvement in the proposed tasks, thus prompting interest in learning early mathematical concepts. Finally, we observed that the pedagogical interventions developed in the Specialized Educational Service, stand out in relation to the regular classroom, as the children showed interest and curiosity in attending this space, due to the activities not only being proposed in either individualized or in small groups, but are also more creative.
\end{abstract}

Keywords: mathematics education; pedagogical interventions; regular classroom; specialized educational service; inclusive education. 
DOI: $10.12957 /$ teias.2021.57858

APRENDIENDO CONCEPTOS MATEMÁTICOS: perspectivas de la educación inclusiva en la ciudad de Gravataí/RS

\section{Resumen}

Este artículo busca reflexionar sobre cómo los diferentes espacios escolares, aula escolar inclusiva regular y Servicio Educativo Especializado, abordan los conceptos matemáticos con los estudiantes. En un extracto de la tesis doctoral, analizamos las intervenciones pedagógicas realizadas en estos espacios, con cuatro alumnos objetivo de educación integrada, matriculados en los primeros años de educación primaria en la ciudad de Gravataí, Rio Grande do Sul (RS). Los resultados de la investigación señalaron que las estrategias de intervención empleadas (juegos pedagógicos, material concreto y tecnologías) potenciaron el aprendizaje matemático de los estudiantes, a través de la lúdica, posibilitando una mayor implicación en las tareas propuestas, despertando así el interés por aprender conceptos matemáticos tempranos. Finalmente, observamos que las intervenciones pedagógicas desarrolladas en el Servicio Educativo Especializado, destacan en relación al aula regular, ya que los niños mostraron interés en asistir a este espacio, por ser las propuestas más atractivas, individualizadas o en pequeño grupos.

Palabras clave: educación matemática; intervenciones pedagógicas; aula regular; servicio educativo especializado; educación inclusiva.

\section{INTRODUÇÃO}

Este artigo apresenta os resultados obtidos na tese de doutorado de Nunes (2018), desenvolvida no Programa de Pós-graduação em Ensino de Ciências e Matemática, da Universidade Luterana do Brasil (PPGECIM/ULBRA). Sua finalidade foi investigar como se constituem as intervenções pedagógicas, visando à aprendizagem de conceitos matemáticos para alunos com Transtorno de Déficit de Atenção/Hiperatividade (TDAH) em Atendimento Educacional Especializado (AEE) no município de Gravataí/RS.

Os objetivos específicos delineados a partir do objetivo geral e do problema de pesquisa foram: i) investigar como os diferentes espaços escolares (sala de aula regular da escola inclusiva e AEE) abordam os conceitos matemáticos com estes alunos; ii) implementar intervenções pedagógicas (ação que envolve 3 etapas distintas: desenvolver, aplicar e avaliar), para alunos com TDAH, enfatizando a aprendizagem de conceitos matemáticos, e iii) pesquisar as percepções de professores em relação ao processo de ensino e de aprendizagem de alunos com TDAH.

A investigação envolveu quatro participantes centrais que integram o público-alvo da educação inclusiva que na época estavam cursando o $4^{\circ}$ ano do ensino fundamental e professores do AEE. A partir desse recorte da pesquisa, analisam-se as intervenções pedagógicas realizadas no AEE e na sala de aula regular, envolvendo a aprendizagem de conceitos matemáticos.

Neste cenário, buscou-se embasamento teórico na Base Nacional Comum Curricular (BNCC, 2018) e nas pesquisas de Skovsmose (2001); Nunes et al (2009); Lorenzato (2011); Rosa Neto (2010); Rückert (2012); Cunha (2012); Yokoyama (2014); Sganzerla (2014); Nunes e Geller (2017a, 2017b, 2017c); Nunes (2018); e Bereta e Geller (2020), que versam sobre a aprendizagem matemática na perspectiva da educação inclusiva.

\section{A EDUCAÇÃO INCLUSIVA NO MUNICÍPIO DE GRAVATAİ́/RS}

Contextualizar a educação inclusiva é algo complexo e requer reflexões sobre um processo que ainda está sendo desenvolvido. Assim, ao se refletir sobre a educação inclusiva, entende-se que a deficiência é caracterizada como "[...] uma restrição física, mental ou sensorial, de natureza 
permanente ou transitória, que limita a capacidade de exercer uma ou mais atividades essenciais da vida diária, causada ou agravada pelo ambiente econômico e social" (BRASIL, 2015) e que, receber o estudante com deficiência na escola pode não efetivar necessariamente sua inclusão.

Em nível nacional, diversos decretos, leis e documentos foram implementados ao longo de muitas décadas em relação aos direitos humanos, acessibilidade e, em especial, a inclusão de Pessoas com Deficiência nas instituições regulares de ensino. Dentre elas, destaca-se a Lei n. 13.146/15 Lei Brasileira de Inclusão da Pessoa com Deficiência (BRASIL, 2015), sancionada em 2015, garantindo uma série de direitos às pessoas com deficiência. A Figura 1 apresenta uma síntese dessa implementação.

Figura 1: Síntese de premissas legais

\begin{tabular}{|c|c|c|c|c|c|c|}
\hline $\begin{array}{l}\text { Declaração } \\
\text { Universal dos } \\
\text { Direitos Humanos } \\
-1948\end{array}$ & $>$ & $\begin{array}{l}\text { Declaração de } \\
\text { Salamanca - } \\
1994\end{array}$ & \multicolumn{3}{|c|}{$\begin{array}{l}\text { Lei n. } 9.394 / 96 \text { - Lei } \\
\text { de Diretrizes e Bases } \\
\text { da Educação } \\
\text { Nacional - } 1996\end{array}$} & $\begin{array}{l}\text { Lei } \mathrm{n}^{\circ} .10 .098 / 00- \\
\text { Lei da } \\
\text { Acessibilidade - } \\
2000\end{array}$ \\
\hline \multicolumn{7}{|l|}{$\sqrt{ }$} \\
\hline $\begin{array}{l}\text { Lei n }{ }^{\circ} .10 .172 / 01- \\
\text { Plano Nacional de } \\
\text { Educação - PNE - } \\
2001\end{array}$ & $\rightarrow$ & \multicolumn{2}{|c|}{$\begin{array}{l}\text { Resolução CNE/CEB n. } \\
\text { 2/01 - Diretrizes Nacionais } \\
\text { para a Educação Especial } \\
\text { na Educação Básica - } 2001\end{array}$} & $>$ & \multicolumn{2}{|c|}{$\begin{array}{c}\text { Decreto } \mathrm{n}^{\circ} \text {. 6.094/07-Garantia do } \\
\text { acesso e permanência no ensino regular e } \\
\text { atendimento às necessidades educacionais } \\
\text { especiais - } 2007\end{array}$} \\
\hline
\end{tabular}

\begin{tabular}{|c|c|}
\hline \multicolumn{1}{|c|}{$\begin{array}{c}\text { Política Nacional de } \\
\text { Educação Especial na } \\
\text { Perspectiva da Educação } \\
\text { Inclusiva - 2008 }\end{array}$} & $\rightarrow \begin{array}{c}\text { Decreto n }{ }^{\circ} \text {. 6.949/09 - } \\
\text { Convenção sobre os } \\
\text { Direitos das Pessoas } \\
\text { com Deficiência - 2009 }\end{array}$ \\
$\qquad$ \\
$\qquad \begin{array}{c}\text { Lei n }{ }^{\circ} \text { 13.146/15 - Lei } \\
\text { Brasileira de Inclusão da } \\
\text { Pessoa com Deficiência - } \\
2015\end{array}$ \\
\hline
\end{tabular}

Fonte: A pesquisa.

A partir destas premissas, de acordo com o INEP/EDUCACENSO (2020), as instituições de ensino da rede pública e privada contemplaram, no ano de 2019, 1.250.967 matrículas de estudantes com deficiência. Esse número refere-se à educação básica, abrangendo a educação infantil, ensino fundamental, ensino médio, educação profissional e educação de jovens e adultos. Destas matrículas, 1.090.805 foram efetivadas em escolas inclusivas e 160.162 em instituições de educação especial.

Tendo em vista que esta pesquisa foi desenvolvida na rede municipal de ensino de Gravataí/RS, buscou-se investigar como a educação inclusiva está estruturada nesse local. Deste modo, verificou-se que o Conselho Municipal de Educação de Gravataí (CMEG), juntamente com a Comissão Especial de Educação Especial, elaborou a Resolução CMEG n. 02/2015, que dispõe sobre as Diretrizes para a Educação Especial no Sistema Municipal de Ensino de Gravataí.

Para garantir o direito de todos a uma educação inclusiva de qualidade, a Resolução CMEG n. 02/2015 foi organizada com fundamento na Constituição Federal (BRASIL, 1988), Estatuto da 
Criança e do Adolescente (BRASIL, 1990), Lei das Diretrizes e Bases da Educação Nacional (BRASIL, 1996), nos Pareceres CNE/CEB no 17/2001 e 13/2009, nas Resoluções CNE/CEB no 02/2001 e 04/2009, nos Decretos n. 5.626/2005, 6.949/2009 e 7.611/11, na Política Nacional da Educação Especial na perspectiva da Educação Inclusiva (BRASIL, 2008), na Convenção Internacional sobre os Direitos das Pessoas com Deficiência (2006) e nas Teses do $3^{\circ}$ Congresso Municipal de Educação de Gravataí (2007). Assim, nesse documento, consta:

Art. 2॰ A Educação Especial, na perspectiva da educação inclusiva, garante o direito à igualdade, trazendo como pressupostos básicos que todos podem aprender, respeitando diferenças de idade, sexo, gênero, etnia, língua, deficiência, classe social ou qualquer outra natureza e assegura: I - a dignidade humana e o direito de cada aluno realizar seus estudos e projetos de trabalho e inserção social; II - a busca da identidade própria de cada aluno, o reconhecimento e valorização de suas diferenças e potencialidades, bem como suas necessidades no processo educativo; III - o desenvolvimento para o exercício da cidadania, da participação social, política, econômica e o cumprimento de seus direitos e deveres (CMEG, 2015, p. 2).

Ainda em relação ao AEE, compreende-se que seu atendimento deve ser de cunho pedagógico e não clínico, sendo que a comprovação da deficiência, por meio de laudo médico, não é imprescindível, entretanto é importante para que os alunos com diagnóstico médico tenham seus direitos garantidos, e também para preservar o trabalho dos profissionais que atuam no AEE (CMEG, 2015).

Nesse contexto, o CMEG (2015) destaca que o Sistema Municipal de Ensino de Gravataí/RS prevê que, na educação básica, poderá ter até dois alunos público-alvo da educação inclusiva, sendo que cada um deve contar como duas matrículas na turma, admitindo-se a lotação máxima de 20 alunos nos Anos Iniciais, 25 alunos nos Anos Finais e no Ensino Médio, e, nas escolas especiais, a previsão do número de alunos por turma deverá estar prevista em seu Regimento, respeitando sua especificidade. Além disso, as escolas podem adotar critérios diferenciados aos estabelecidos anteriormente, se a sala de aula não apresentar condições de espaço adequado e/ou de acessibilidade.

O CMEG (2015, p. 5) afirma no artigo 13 que "[...] a SMED em parceria com as Secretarias da Saúde e Assistência Social criará o Centro de Atendimento Educacional Especializado (CAEE)", sendo que este Centro irá contar com pelo menos um dos seguintes profissionais: professor especialista em educação especial, psicólogo, assistente social, fonoaudiólogo, terapeuta ocupacional, fisioterapeuta, psiquiatra e neurologista. Cabe ainda ressaltar que:

O CAEE fará avaliação especializada e atendimento multidisciplinar dos alunos da rede municipal, público-alvo da Educação Especial, que demandarem atendimento mais específico, cujo AEE da escola não for suficiente para atender as suas necessidades. $\$ 1^{\circ} \mathrm{O}$ CAEE poderá realizar o AEE dos alunos, públicoalvo da Educação Especial, cuja escola ainda não tenha esta oferta. O CAEE deverá ter Projeto Político Pedagógico (PPP), regimento e autorização de funcionamento pelo Conselho Municipal de Educação (CMEG, 2015, p. 6).

Para atuar diante das dificuldades e/ou necessidades de aprendizagens dos alunos públicoalvo da educação inclusiva, o CMEG (2015, p. 12), no artigo 37, compreende que as escolas deverão “[...] garantir as adaptações curriculares necessárias, levando em consideração o que o aluno deve aprender, como pode aprender e de que forma o processo de aprendizagem será mais eficiente". 
Nessa perspectiva, a adaptação curricular deve ser compreendida como um "[...] instrumento individual que irá possibilitar o planejamento e dimensionamento do que, quando e como ensinar o aluno com deficiência ou não, constituindo-se como possibilidades educacionais frente às dificuldades de aprendizagem do mesmo [...]", conforme CMEG (2015, p. 18), buscando, assim, tornar o currículo mais adequado as suas peculiaridades. Desse modo, a adaptação curricular é um trabalho coletivo com a equipe pedagógica da escola e, também, com a participação constante da família, de modo que esse processo não ocorra de forma isolada, apenas com o professor.

Vale ressaltar, no entanto, que há distintos alunos que, devido à deficiência, acabam recebendo adaptações muito significativas em seus currículos, porém demonstram não terem "[...] capacidade de desenvolver o estabelecido nos artigos 24, 26 e no artigo 32, I da Lei n 9.394/96. Sua escolarização não deve ser definida com base no que não consegue aprender, mas no que a escola pode ensinar". Assim, conforme o $\operatorname{CMEG}(2015$, p. 19):

\begin{abstract}
A escola, ao definir um currículo tão diferenciado dos demais, deve ter reunido uma série de instrumentos de avaliações e adaptações realizadas a fim de comprovar esta necessidade, garantindo sempre a participação do Núcleo de Educação Especial (NEE) da Secretaria Municipal de Educação. Este currículo, denominado currículo funcional, deverá ser direcionado ao desenvolvimento de habilidades mais práticas, relacionadas a seu cotidiano, a fim de oportunizar e priorizar sua autonomia e participação social. Para estes alunos, que não conseguirem atingir o nível exigido para a conclusão do Ensino Fundamental, será assegurado um Certificado de Terminalidade Específica, dado pela escola em forma de histórico descritivo das habilidades desenvolvidas pelo aluno.
\end{abstract}

Em Gravataí, os professores que atuam no AEE são responsáveis por elaborar o Plano de Desenvolvimento Individual (PDI), que serve para registrar a avaliação, adaptar o currículo e desenvolver as intervenções pedagógicas, conforme as necessidades e especificidades de cada aluno público-alvo da educação inclusiva (POKER et al., 2013; GONZÁLEZ, 2002). Destacamos que em agosto de 2020, iniciaram-se, neste município, as obras para a construção do Complexo de Educação Especial Irmã Soledade, que deverá contemplar aproximadamente 1,3 mil dos alunos que integram o público-alvo da educação inclusiva. Além disso, três serviços relevantes serão concentrados no Complexo, sendo eles: a Escola Municipal de Educação Especial (Cebolinha), a Escola Municipal de Ensino Fundamental Especial para Surdos (EMEES) e o CAEE.

\title{
APRENDIZAGEM DE CONCEITOS MATEMÁTICOS
}

Embora ainda suscite reflexões, a BNCC constitui-se como uma referência nacional para a elaboração de currículos diversos, compreendendo também a educação na perspectiva inclusiva, entende-se que seja imprescindível contemplar nos currículos a diversidade cultural, a equidade e $\mathrm{o}$ respeito às diferenças.

A partir da BNCC e da política da educação inclusiva brasileira, fundamentadas no princípio da igualdade e no exercício dos direitos e deveres do cidadão, o exercício da cidadania implica em participar efetivamente dos diversos segmentos da sociedade. É importante salientar a utilização de diferentes linguagens como, por exemplo, corporal, visual, verbal, sonora, indicadas a partir das Competências Gerais da Educação Básica, previstas na BNCC (BRASIL, 2018), bem como, conhecimentos das linguagens matemática e científica como meios de expressão, de troca de experiências, que produzam significados, possibilitando seu entendimento. Assim: 
[...] infere-se que conceitos científicos e matemáticos fazem parte da vida em sociedade, sendo importante contextualizá-los à realidade e às especificidades de cada estudante de inclusão, considerando o seu contexto social e como ele interage com o meio, para que tais situações possam potencializar seu desenvolvimento cognitivo (BERETA, GELLER, 2020, p. 101).

Ou seja, é fato que o estudante já traz consigo conhecimentos informais, que experiencia nas relações sociais, no seu cotidiano, com elementos científicos e matemáticos que podem agregar experiências significativas ao seu processo de aprendizagem.

Sobre a utilização de material concreto ou materiais manuseáveis (ROSA NETO, 2010), como: tampinhas, palitos, feijões, botões, material dourado, dedos das mãos (RÜCKERT, 2012; YOKOYAMA, 2014), dentre outros, vale ressaltar que estes, bem como os jogos pedagógicos e as tecnologias, são fundamentais, conforme Nunes (2018), para a aprendizagem dos conceitos matemáticos, especialmente nas atividades que envolvem a construção do número, os sete processos mentais básicos (correspondência, comparação, classificação, sequenciação, seriação, inclusão e conservação) e a resolução de problemas.

Para Lorenzato (2011, p. 93), “[...] num primeiro momento devem-se realizar atividades com o corpo e/ou objetos, depois com imagens (desenhos, figuras) e, finalmente, com símbolos". Assim, "[...] o professor e as crianças podem juntar embalagens vazias: latas, copos de plástico, caixas (de sabonete, de fósforo, de sapatos), tampas e etc.", para desenvolverem atividades, utilizando-se de materiais manuseáveis (sucatas, por exemplo) como recursos para a aprendizagem da matemática (LORENZATO, 2011).

Segundo os apontamentos de Yokoyama (2014, p. 31) “[...] os dedos das mãos talvez sejam a primeira ferramenta matemática usada no auxílio da contagem e de cálculos”, ressaltando que:

A utilização dos dedos das mãos, pode ser uma aliada na aquisição do conceito de número pelas crianças com Síndrome de Down. Pelo fato de estar trabalhando a mesma região do cérebro que as habilidades numéricas, pelo desenvolvimento da coordenação motora para utilizar no procedimento da contagem e por proporcionar ao participante uma sensação dos números, mais que uma simples visualização (YOKOYAMA, 2014, p. 33).

De acordo com Nogueira (2011), o estudante para realizar a contagem deve estar apto, a reconhecer a "unidade", sendo uma definição vinculada aos objetos quando se igualam as diferenças e, constituída a partir da abstração, antes de ser devidamente nomeada. Essa noção vale também para a aprendizagem de correspondências, classes e ordenação. Entretanto, há a necessidade de se manipular objetos antes de nomeá-los, a fim de desencadear o processo de abstração, as tarefas de contagem e a construção numérica.

$\mathrm{Na}$ Figura 2, verifica-se que o material dourado é composto, conforme Rosa Neto (2010, p. 67), por "[...] peças de madeira de quatro tipos: cubinho de $1 \times 1 \times 1 \mathrm{~cm}^{3}$, barra de $1 \times 1 \times 10$ $\mathrm{cm}^{3}$, placa de $1 \times 10 \times 10 \mathrm{~cm}^{3}$ e cubo de $10 \times 10 \times 10 \mathrm{~cm}^{33}$. Em relação ao material dourado, Rosa Neto (2010, p. 67) afirma que "[...] serve para trabalhar a base decimal, áreas e volumes, propriedades das operações, produtos notáveis". Infere também que "[...] permite trocar dez cubinhos soltos por uma barra de dez cubinhos presos, portanto, faz agrupamentos decimais". 
Figura 2: Material Dourado ${ }^{1}$
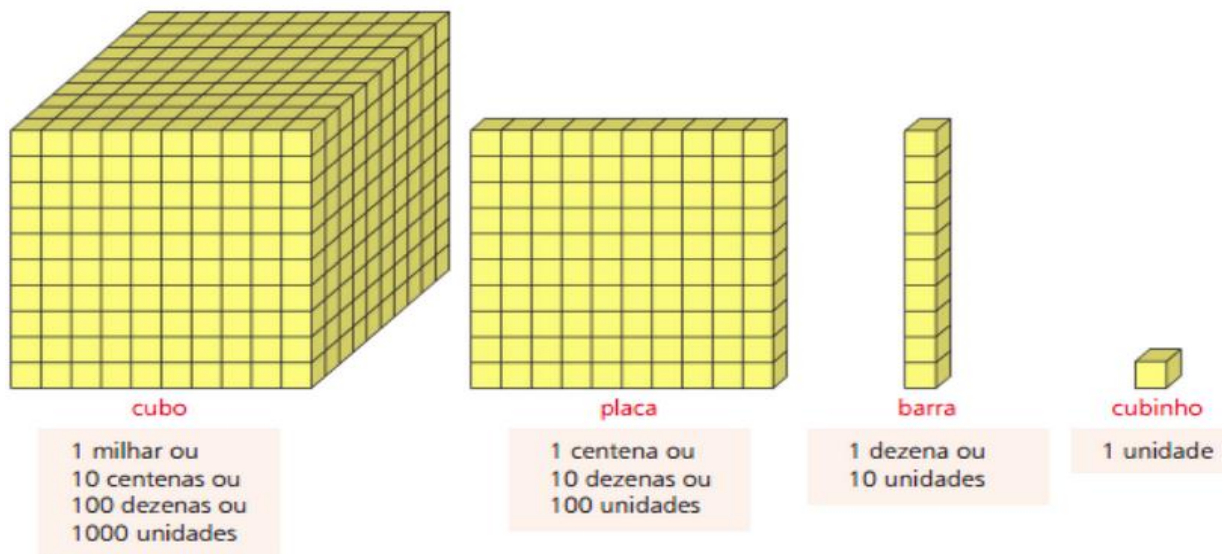

Fonte: Adaptado de Rosa Neto (2010).

Sobre o material dourado, é interessante observar que

A manipulação e o uso desse recurso podem ajudar na compreensão da adição e subtração com dezenas e reforça a noção de troca no sistema posicional, propiciando aos alunos descobrirem as relações entre as peças, como, por exemplo, uma barra é composta por dez cubinhos, uma placa por dez barras e o cubo por dez placas. O mesmo é constituído para representar um sistema de agrupamento, associando o modelo didático com o conceito matemático. (SGANZERLA, 2014, p. 45)

Em relação à aprendizagem, e especificamente a aprendizagem matemática, é fundamental compreender quais são as dificuldades encontradas pelo estudante e por que as apresenta. Não é tarefa simples, mas a análise de suas potencialidades e da forma de agir e pensar desse aluno, poderá se constituir em fator decisivo para o seu processo de inclusão. Será no espaço escolar que o estudante aprenderá os símbolos matemáticos e seus significados, as quantidades e as relações entre elas, relacionando o conhecimento informal e a aprendizagem formal, estabelecendo sua compreensão entre quantidades, relações e símbolos.

\section{ASPECTOS METODOLÓGICOS}

Para esta pesquisa ${ }^{2}$ utilizamos a abordagem qualitativa, e os dados foram considerados por meio de uma análise descritiva interpretativa. De acordo com Rosenthal (2014, p. 26), o método interpretativo é conveniente "[...] para fenômenos frequentes ou mesmo raros - de difícil análise ulterior".

\footnotetext{
1 A $\quad$ imagem está disponível em http://pacto.mec.gov.br/images/pdf/cadernosmat/PNAIC MAT Caderno\%204 pg001-088.pdf.

${ }^{2} \mathrm{O}$ projeto de pesquisa inicialmente foi aprovado pela Comissão de Pós-Graduação da Universidade. A pesquisa não passou por avaliação ética pelo Sistema CEP/CONEP, uma vez que a coleta dos dados da pesquisa iniciou em período anterior à Resolução n. 510, de 7 de abril de 2016, do Conselho Nacional de Saúde. Sendo assim, observando procedimentos éticos, foi elaborado, antes da realização da pesquisa, um Termo de Consentimento Livre e Esclarecido que foi assinado pelos participantes, ou representantes legais, com o objetivo de conscientizá-los acerca das ações e intenções dos pesquisadores.
} 
A pesquisa foi realizada ao longo de três anos e contou com o apoio do Setor de Educação Especial, vinculado à Secretaria Municipal de Educação (SMED) de Gravataí/Rio Grande do Sul/Brasil, para identificar os participantes da investigação, sendo que o critério inicial teve como finalidade mapear os alunos diagnosticados com Transtorno de Déficit de Atenção/Hiperatividade (TDAH) (NUNES, GELLER, 2017a, 2017b, 2017c).

Entretanto, conforme Nunes e Geller (2017a, 2017b, 2017c), já cientes de que o TDAH não garantiria o atendimento educacional especializado, pois não caracteriza o público-alvo da educação inclusiva, fez-se necessário contatar as 45 escolas de ensino fundamental da rede municipal de ensino de Gravataí que têm Sala de Recursos Multifuncional (SRM) - local este em que as crianças recebem o AEE, para verificar quais estudantes tinham o TDAH associado a uma deficiência, pois é a deficiência que garantiria esse atendimento.

De acordo com Nunes e Geller (2016), o mapeamento foi concluído no início do ano letivo e verificou-se que quatro alunos, com idades entre 10 e 12 anos, estavam cursando o $4^{\circ}$ ano do ensino fundamental e tinham diagnóstico de TDAH associado a Deficiência Intelectual (DI). A pesquisa foi realizada na SRM e na sala de aula regular de três escolas de ensino fundamental da rede municipal de ensino de Gravataí/Rio Grande do Sul.

Deste modo, assim que os participantes da investigação foram definidos, conforme evidenciam Nunes e Geller (2017a, 2017b, 2017c), solicitou-se autorização da SMED, das escolas, das professoras e das famílias, para realizar as intervenções pedagógicas com os estudantes no AEE e na sala de aula regular, voltadas à aprendizagem de conceitos matemáticos.

As intervenções pedagógicas foram realizadas de modo colaborativo, envolvendo a participação das pesquisadoras e das professoras atuantes no AEE e na sala de aula regular. Para tanto, utilizou-se os seguintes instrumentos de coletas de dados: entrevistas e/ou aplicação de questionários com as professoras do AEE e da sala de aula regular, sondagem sobre o desempenho na disciplina de matemática dos alunos, participantes da pesquisa, a partir de atividades matemáticas, anamneses, histórico, planos de desenvolvimento individual (PDI), adaptações curriculares e pareceres escolares da sala regular e do AEE, desenvolvimento de ações para o processo de aprendizagem matemática, acompanhamento dos alunos (sala regular e AEE) e implementação (planejamento, desenvolvimento e avaliação) das intervenções pedagógicas voltadas para a educação matemática na perspectiva da educação inclusiva.

\section{ANÁLISE E DISCUSSÃO DOS RESULTADOS}

Neste artigo, optamos por apresentar os resultados das intervenções pedagógicas realizadas no AEE e na sala de aula regular com três dos quatro estudantes que integram a pesquisa (Alunos A, B e P). As análises envolveram distintas estratégias de intervenção para a aprendizagem dos conceitos matemáticos, como a utilização de material concreto ou manipulável (tampinhas coloridas, material dourado e dedos das mãos), jogos pedagógicos e recursos tecnológicos.

Uma das primeiras intervenções pedagógicas realizadas no AEE com o Aluno A estava relacionada ao uso do material dourado. A professora explicou o que era unidade, dezena e centena, apresentando com o material que, quando se chega a 10 unidades, os cubinhos são substituídos por 1 barra, e assim por diante, conforme destacado por Rosa Neto (2010) e apresentado na Figura 2. Durante as explicações, a professora do AEE fez alguns questionamentos para a criança e foi possível perceber que ela sabia identificar e quantificar as unidades e as dezenas, porém, em determinadas situações, acabava se confundindo e chamava as barras de unidades, ao invés de pronunciar dezenas. Tal situação está relacionada à desatenção que é um dos comportamentos 
típicos do TDAH. Na Figura 3, apresentamos as atividades realizadas com o Aluno A durante atendimento na SRM.

Figura 3: Atividades realizadas no AEE com o material dourado (Aluno A)

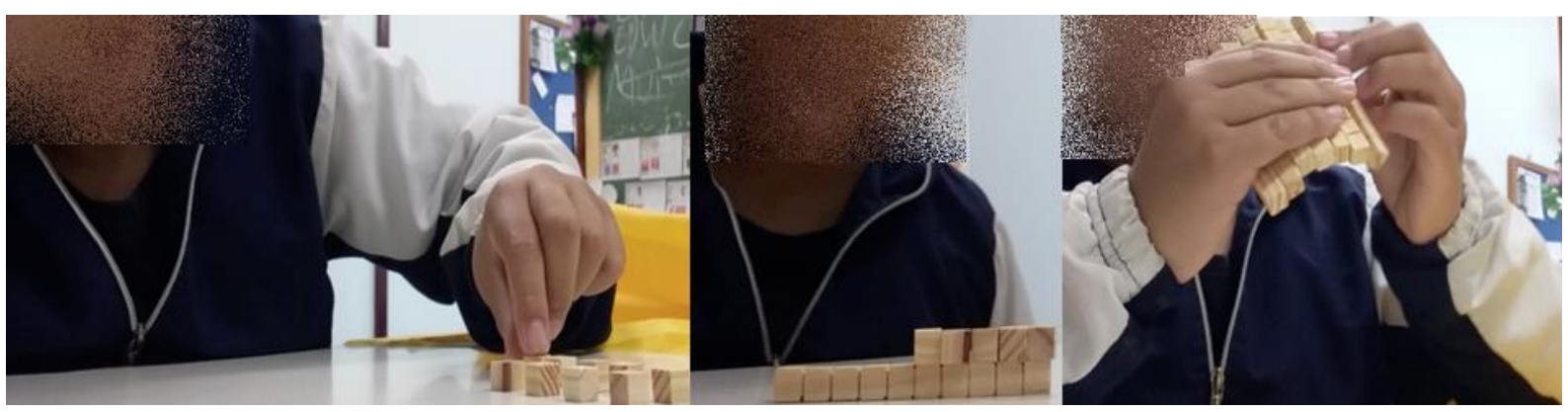

Fonte: A pesquisa.

De acordo com Nunes e Geller (2016, p. 116-117):

Logo após, a professora decidiu realizar outra atividade que envolvesse a utilização do material dourado, então começou a mostrar números em E.V.A., para o aluno representar. O primeiro número apresentado foi o número 9, e a criança conseguiu representar corretamente e ainda afirmou que eram " 9 unidades". Depois ele tinha de representar o número 15, então apresentou duas barras, mas em seguida ele se deu conta que estava equivocado e trocou uma das barras por 5 unidades, representando, assim, a quantidade de forma adequada.

A partir do exposto e analisando as imagens da Figura 3, faz-se necessário ressaltar que, na primeira tarefa, a qual consistia em representar 9 unidades com o material dourado, o aluno realizou a proposta de forma adequada, mas as peças ficaram desorganizadas sobre a mesa (aqui salientamos outra característica do TDAH, a dificuldade de se organizar com os materiais). No entanto, após conversa e orientação da professora do AEE, é possível verificar já na segunda tarefa — representar o número 15 com o material dourado - , que o estudante conseguiu estabelecer uma organização das peças que estavam dispostas sobre a mesa. Além disso, foi possível perceber, no momento, a expressão facial de alegria da criança, ao receber palavras de incentivo da professora quando está realizando as tarefas e, mesmo quando apresentava dificuldades, não deixava de receber apoio.

De forma espontânea, o Aluno A pediu para representar o número $70 \mathrm{com}$ o material. $\mathrm{Na}$ sequência da Figura 3, verificamos que ele segura firme em uma das mãos 7 barrinhas e com os dedos da outra mão está contando da seguinte forma: “10, 20, 30, 40, 40, 60, 70. Tem 70”. Neste cenário, concordamos com Sganzerla (2014, p. 43) ao afirmar que "[...] o uso e a exploração do material concreto, por parte dos professores e alunos, poderão facilitar ações tanto para o professor ensinar, quanto para o aluno aprender".

Também foi implementada uma intervenção pedagógica com o Aluno A, relacionada à classificação, que envolveu um total de 40 fichas, sendo elas: 5 círculos pequenos azuis, 5 círculos pequenos vermelhos, 5 círculos grandes azuis, 5 círculos grandes vermelhos, 5 quadrados pequenos azuis, 5 quadrados pequenos vermelhos, 5 quadrados grandes azuis e 5 quadrados grandes vermelhos. De acordo com Lorenzato (2011, p. 111), o objetivo dessa atividade é "[...] classificar considerando mais de um atributo (cor, tamanho e forma)".

As fichas foram colocadas sobre a mesa de forma desordenada, e solicitou-se que o aluno organizasse em grupos todas as fichas que podiam ficar juntas, ou seja, que se parecessem muito. 
Então, o aluno olhou para as fichas e falou: "vou fazer desse jeito, primeiro todas vermelhas, depois as vermelhas grandes e pequenas". Na Figura 4, o Aluno A estava desenvolvendo a atividade que lhe foi proposta. Cabe destacar que o mesmo processo de classificação espontânea ocorreu com as fichas azuis.

Figura 4: Atividade de classificação realizada no AEE (Aluno A)

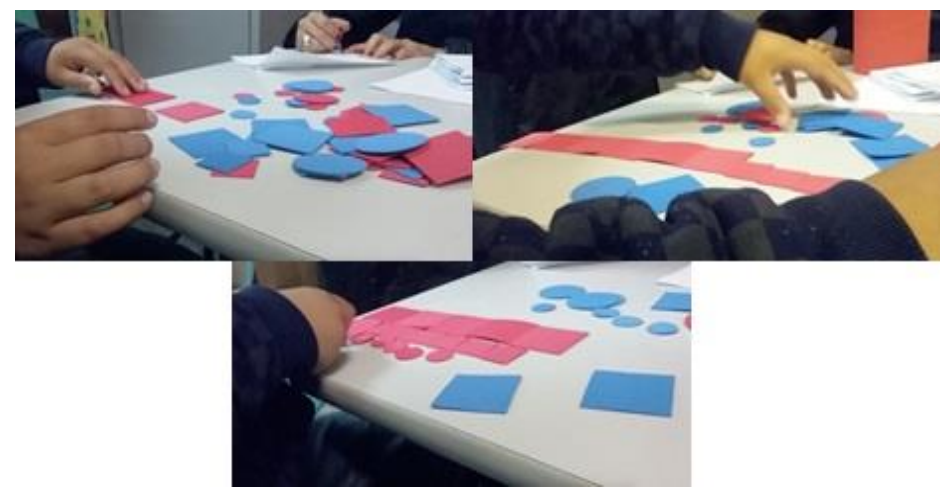

Fonte: Nunes (2018, p. 147).

Assim, a primeira classificação do aluno foi organizar as fichas por cores, montando dois grandes grupos, sendo um de cor vermelha e um de cor azul. Além disso, logo que esse aluno visualizou as fichas, já percebeu que estas poderiam ser organizadas de outras formas, pois ele destaca "vermelhas grandes e pequenas", ou seja, sem auxílio da pesquisadora, foi capaz de visualizar outras possibilidades, além do critério cor.

Em seguida, a pesquisadora pediu para o aluno organizar as fichas, também em dois grupos, porém de uma outra maneira, colocando juntas as que se parecem. Então o aluno disse: "dá para pegar tudo que é grande e tudo que é pequeno". A pesquisadora indicou: "isso mesmo, mas será que podemos organizar de uma outra forma? O que você acha?"; o aluno olhou para as fichas e afirmou: "dá pra botar os quadrados num monte e as bolinhas em outro".

Em relação ao Aluno $\mathrm{P}$, constatou-se que ele optou por utilizar material de contagem (tampinhas de medicamento) como estratégia para resolver um problema matemático na sala de aula regular, conforme destacado por Rosa Neto (2010). Além disso, na Figura 5, é possível verificar que o aluno conseguiu organizar as tampinhas, agrupando-as de duas em duas e, também, formar conjuntos, sendo que o primeiro correspondia a 12 figurinhas, e o segundo, a 8 figurinhas.

Figura 5: Problema matemático resolvido pelo Aluno P na sala de aula regular

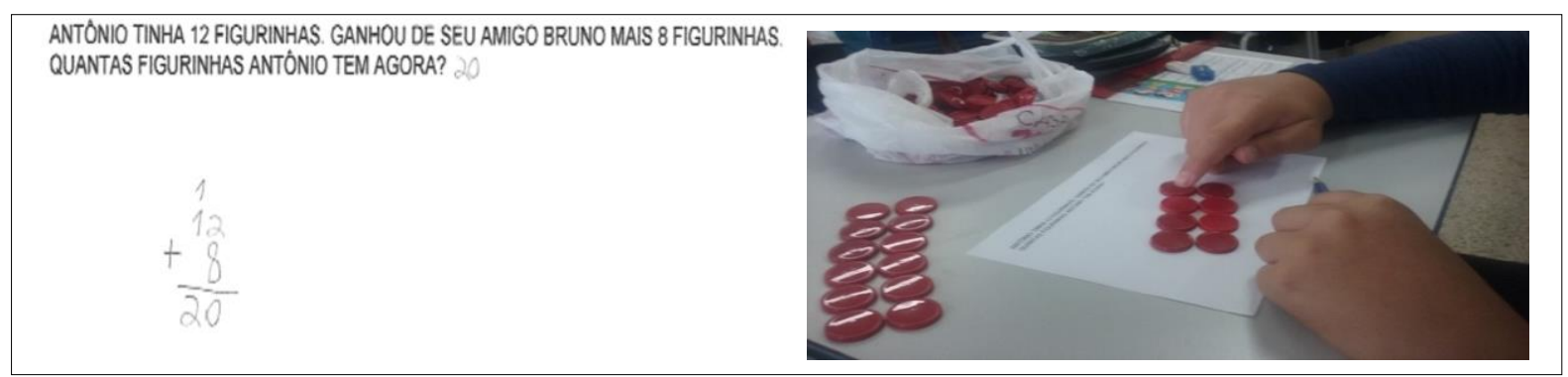

Fonte: Nunes (2018, p. 167). 
$\mathrm{Na}$ sequência, o aluno identificou que no primeiro conjunto havia 12 tampinhas e, posteriormente, continuou a contagem no segundo conjunto, encontrando o número 20 como resposta. No problema percebeu-se que o Aluno P foi capaz de selecionar a maior quantidade, para continuar a contagem, tocando os objetos com os dedos para contar, conforme indicado por Rückert (2012) e Yokoyama (2014). Neste contexto, busca-se apoio teórico na pesquisa de Rückert (2012, p. 24), ao destacar que "[...] em uma etapa posterior, a criança já seleciona, das duas quantidades, a maior para começar (contar a partir do maior ou mínimo), pois esse procedimento é ainda mais econômico e preciso".

No entanto, cabe destacar que uma das dificuldades do Aluno P se encontrava na leitura e na interpretação dos problemas matemáticos, pois, além de ter TDAH e DI, o aluno também apresenta Transtorno da Fala ou da Linguagem, e isso acaba sendo um obstáculo para interpretar os problemas matemáticos.

De acordo com o parecer do segundo trimestre de 2017, o Aluno P "[...] necessita de auxílio constante, de um monitor e professor, durante as aulas de língua portuguesa e de matemática, quando há a leitura de textos e problemas matemáticos". Por isso, no momento de resolver os problemas matemáticos, o aluno sempre estava acompanhado de um adulto, para auxiliá-lo na leitura e interpretação do problema.

Na Figura 6, apresenta-se um aplicativo gratuito, denominado Kids Math Games (com acesso via celular), que foi utilizado com os alunos para trabalhar o reconhecimento dos números e das quantidades, bem como um quebra-cabeça que foi confeccionado pela pesquisadora, para auxiliar as crianças no entendimento da correspondência.

Figura 6: Jogo eletrônico e quebra-cabeça dos números (Alunos A, B e P)

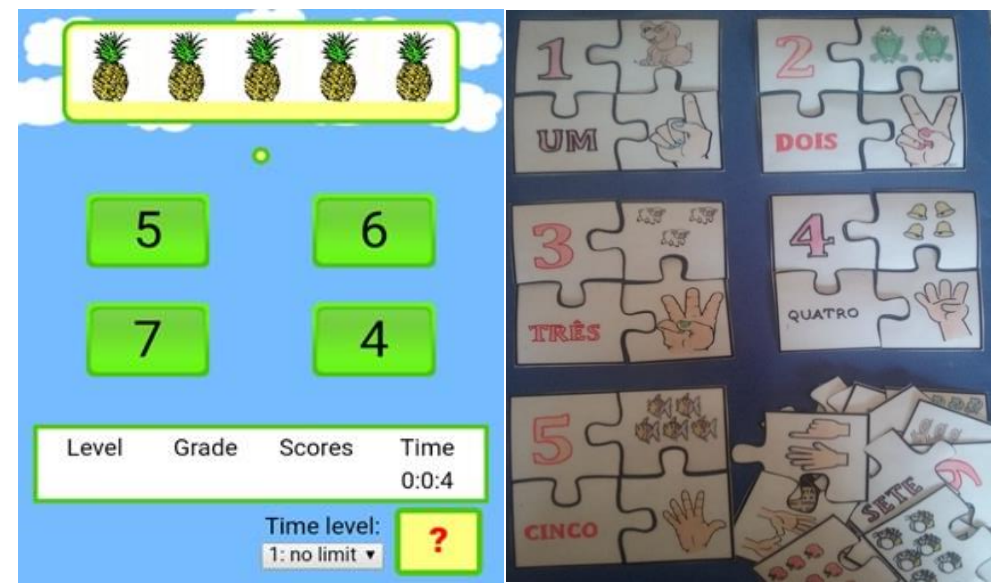

Fonte: Adaptado de Nunes e Geller (2017d, p. 9).

Durante as intervenções pedagógicas envolvendo as tecnologias, percebeu-se que os alunos ficaram mais interessados pelas atividades propostas. No caso dos Alunos A, B e P, constatou-se que os três foram capazes de estabelecer a correspondência termo a termo, conseguindo concluir os 5 níveis do game que envolvia o estabelecimento de relações entre números e quantidades, no caso, de frutas e animais até o número 30.

No quebra-cabeça dos números, as crianças conseguiram encaixar as peças com sucesso, sendo que também foram trabalhadas oralmente as quantidades apresentadas em cada situação, em que a pesquisadora questionava quantos cachorros havia ou quantos dedos das mãos estavam 
levantados e assim por diante. Nessa atividade, também era possível trabalhar a classificação, pois as crianças poderiam organizar as peças do quebra-cabeça por numeral, escrita por extenso, animais/objetos e dedos das mãos. No entanto, os Alunos A, B e P ficaram livres para resolver o quebra-cabeça, mas nenhum teve a iniciativa de organizar as peças, sendo necessário a intervenção da pesquisadora, para auxiliar na organização das peças.

Neste cenário, busca-se suporte teórico na BNCC (2018) e em autores como Cunha (2012), Yokoyama (2014), Nunes et al (2009) ao mencionarem que os recursos didáticos como material concreto, jogos pedagógicos e tecnologias são estratégias de intervenção que têm um papel importante nos processos de ensino e de aprendizagem da matemática, pois as crianças aprendem a partir de suas especificidades e também de forma. Além disso, o CMEG (2015) ressalta a importância e a necessidade de realizar a adaptação curricular das crianças público-alvo da educação inclusiva, pois é por meio deste que os professores vão buscar estratégias, para planejar, verificando as possibilidades educacionais frente às peculiaridades e dificuldades de aprendizagem dessas crianças, procurando sempre pelo apoio da equipe pedagógica e das famílias.

Tendo em vista a BNCC (BRASIL, 2018), verifica-se que a área de matemática é ampla, contemplando, entre outros aspectos, o desenvolvimento de competências fundamentais para o letramento matemático: raciocínio, representação, comunicação e argumentação. Assim, a aprendizagem de conceitos matemáticos pode promover melhor compreensão de diferentes aspectos da vida em sociedade para todos estudantes.

O desenvolvimento do letramento matemático, definido como as competências e habilidades de raciocinar, representar, comunicar e argumentar matematicamente, de modo a favorecer o estabelecimento de conjecturas, a formulação e a resolução de problemas em uma variedade de contextos, utilizando conceitos, procedimentos, fatos e ferramentas matemáticas (BRASIL, 2018, p. 268).

Skovsmose (2001) aponta a importância dos conhecimentos matemáticos articulados às atividades do dia a dia, às relações sociais, refletindo que sua ausência poderá interferir na relação do indivíduo com o mundo, inibindo sua postura crítica e sua tomada de decisões.

\section{CONSIDERAÇÕES FINAIS}

A partir das intervenções pedagógicas e das análises realizadas, compreendemos que as estratégias utilizadas (jogos pedagógicos, material concreto e tecnologias), potencializaram a aprendizagem de conceitos matemáticos dos alunos, fazendo com que apresentassem um maior envolvimento e interesse nas atividades. Daí surge a importância de conhecer a realidade dos estudantes, para que seja possível planejar e adaptar as atividades, conforme suas especificidades e interesses, enfatizando suas potencialidades e auxiliando nas suas dificuldades.

Além disso, observamos, no decorrer das intervenções pedagógicas, sobretudo no AEE, que as atividades desenvolvidas nesse espaço ocorrem de forma mais criativa, individualizada ou em pequenos grupos. Por isso, os estudantes demostraram muito interesse em frequentar esse espaço. Na sala de aula regular, também são utilizados materiais concretos, como tampinhas de garrafa, por exemplo, para trabalhar com a contagem, mas percebemos que, em muitas situações, as crianças perdem o interesse pelas atividades, seja pela dificuldade de copiar as tarefas do quadro, seja pelo tipo de atividade que, na maioria das situações, ocorria de forma mecânica.

Por fim, enfatizamos que não se pretende, com esta pesquisa, assumir um viés prescritivo, uma vez que cada estudante possui seu próprio ritmo de aprendizagem. No contexto educacional 
não existe um formato pronto, mas isso não significa que alguns caminhos já percorridos não possam ser refletidos e/ou adotados, desde que se respeite o tempo de desenvolvimento de conceitos de cada estudante. Diante do exposto, buscou-se resgatar frequentemente as potencialidades e enfatizar as peculiaridades de cada estudante, demonstrando confiança na sua capacidade de aprendizagem.

\section{REFERÊNCIAS}

BERETA, Mônica Silveira; GELLER, Marlise. Adaptação curricular e o ensino de ciências e matemática. In: KAIBER, Carmen Teresa; GROENWALD, Claudia Lisete Oliveira (org.) Ensino e aprendiragem em ciências e matemática: referenciais, práticas e perspectivas. Canoas: ULBRA, 2020. p. 95-107.

BRASIL. Constituição da República Federativa do Brasil de 1988. Brasília, Senado Federal, 1988.

BRASIL. INEP/EDUCACENSO 2020. Instituto Nacional de Estudos e Pesquisas Educacionais Anísio Teixeira. Sinopse estatística da educação básica 2019. Brasília.

BRASIL. Lei n. 8.069 de 13 de julho de 1990. Dispõe sobre o Estatuto da Criança e do Adolescente e dá outras providências. Brasília, 1990.

BRASIL. Lei n. 9.394 de 20 de dezembro de 1996. Estabelece as Diretrizes e Bases da Educação Nacional. Brasília, 1996.

BRASIL. Ministério da Educação. Conselho Nacional de Educação. Câmara de Ensino Básico. Diretrizes Nacionais para a Educaşão Especial na Educação Básica. Brasília, 2001.

BRASIL. Política Nacional de Educação Especial na Perspectiva da Educação Inclusiva. Brasília: MEC/SECADI, 2008.

BRASIL. Institui Diretriz̨es Operacionais para o Atendimento Educacional Especializado na Educação Básica, modalidade Educação Especial. Ministério da Educação. Conselho Nacional de Educação. Resolução n. 04 de 2 de outubro de 2009. Brasília: CNE/CEB, 2009.

BRASIL. Decreto n. 7.611, de 17 de novembro de 2011. Dispõe sobre a educação especial, o atendimento educacional especializado e dá outras providências. Brasília, 2011.

BRASIL. Lei n. 13.146, de 6 de julho de 2015. Lei Brasileira de Inclusão da Pessoa com Deficiência (Estatuto da Pessoa com Deficiência). Brasília, 2015.

BRASIL. Base Nacional Comum Curricular: Educação é a base. Brasília: MEC/Secretaria de Educação Básica, 2018.

CONSELHO MUNICIPAL DE EDUCAÇÃO DE GRAVATAÍ. Resolução CMEG n. 02/2015. Dispõe sobre as diretrizes para a Educação Especial no Sistema Municipal de Ensino de Gravataí. Gravataí, 2015.

CUNHA, Eugênio. Autismo e inclusão: psicopedagogia e práticas educativas na escola e na família. Rio de Janeiro: Wak, 2012.

GONZÁLEZ, José Antonio Torres. Educação e diversidade: bases didáticas e organizativas. Porto Alegre: Artes Médicas, 2002.

LORENZATO, Sérgio. Educação infantil e percepşão matemática. Campinas, São Paulo: Autores Associados, 2011.

NOGUEIRA, Clélia Maria Ignatius. Pesquisas atuais sobre a construção do conceito de número: para além de Piaget? Educar em Revista, Curitiba, Brasil, n. especial 1, p. 109-124, 2011. 
NUNES, Camila da Silva. Alunos com TDAH em Atendimento Educacional Especializado: um estudo sobre a aprendizagem de conceitos matemáticos. Tese (Doutorado) - Universidade Luterana do Brasil, Canoas, 2018.

NUNES, Camila da Silva; GELLER, Marlise. Reflexões sobre o processo de aprendizagem matemática no Atendimento Educacional Especializado. Educação Matemática em Revista - RS, v. 2, n. 17, p. 107-120, 2016.

NUNES, Camila da Silva; GELLER, Marlise. A percepção dos professores diante da inclusão de crianças com TDAH. In: EDUCERE - Congresso Nacional de Educação, 13., 2017, Curitiba. Anais eletrônicos... Curitiba: PUC-Paraná, 2017a. p. 1535-1551.

NUNES, Camila da Silva; GELLER, Marlise. Alumno con parálisis cerebral, deficiencia intelectual y TDAH: reflexiones sobre el proceso de construcción del número. Paradigma (Maracay), v. 38, p. 205-236, 2017b.

NUNES, Camila da Silva; GELLER, Marlise. Os desafios do Atendimento Educacional Especializado: observações sobre a aprendizagem de conceitos matemáticos. Imagens da Educação, v. 7, p. 37-50, 2017c.

NUNES, Camila da Silva; GELLER, Marlise. As tecnologias na educação inclusiva. In: Seminário Nacional Desafios da Educação no Século XXI, 1., 2017, Farroupilha. Anais eletrônicos... Farroupilha, Rio Grande do Sul, 2017d. p. 1-12.

NUNES, Terezinha et al. Educação matemática: números e operações numéricas. 2. ed. São Paulo: Cortez, 2009.

POKER, Rosimar Bortolini; MARTINS, Sandra Eli Sartoreto de Oliveira; OLIVEIRA, Anna Augusta Sampaio de; MILANEZ, Simone Ghedini Costa; GIROTO, Claudia Regina Mosca. Plano de Desenvolvimento Individualizado para o Atendimento Educacional Especializado. São Paulo: Cultura Acadêmica, 2013.

ROSA NETO, Ernesto. Didática da matemática. São Paulo: Ática, 2010.

ROSENTHAL, Gabriele. Pesquisa social interpretativa: uma introdução. Porto Alegre: EDIPUC-RS, 2014.

RÜCKERT, Sarah Louise Sonntag. Memória de trabalbo em crianças e adolescentes com TD AH e dificuldade ou transtorno na matemática. 2012. 72f. Dissertação (Mestrado em Educação) - Universidade Federal do Rio Grande do Sul, Porto Alegre, 2012.

SGANZERLA, Maria Adelina Raupp. Contátil: potencialidades de uma Tecnologia Assistiva para o ensino de conceitos básicos de matemática. 2014. 118f. Dissertação (Mestrado em Ensino de Ciências e Matemática) - Universidade Luterana do Brasil, Canoas, 2014.

SKOVSMOSE, Ole. Educação matemática crítica: a questão da democracia. 4. ed. Campinas: Papirus, 2001.

YOKOYAMA, Leo Akio. Matemática e sindrome de Down. Rio de Janeiro: Ciência Moderna, 2014. 


\section{Informações das autoras}

Camila da Silva Nunes

Prefeitura Municipal de Canoas

Faculdade Unina

E-mail:professoracamilanunes@gmail.com

ORCID: http://orcid.org/0000-0002-9750-2386

Link Lattes: http://lattes.cnpq.br/8113613744283531

Marlise Geller

Universidade Luterana do Brasil

E-mail: marlise.geller@gmail.com

ORCID: https://orcid.org/0000-0002-9640-2666

Link Lattes: http://lattes.cnpq.br/4777298613817310 